\title{
miR-489-3p overexpression inhibits lipopolysaccharide-induced nucleus pulposus cell apoptosis, inflammation and extracellular matrix degradation via targeting Toll-like receptor 4
}

\author{
LING DONG $^{1}$ and $\mathrm{BO} \mathrm{DONG}^{2}$ \\ ${ }^{1}$ Department of Rehabilitation Medicine, Guizhou Orthopedics Hospital, Guiyang, Guizhou 550000; \\ ${ }^{2}$ Pain Rehabilitation Department of TCM Orthopedic Center, Honghui Hospital, \\ Xi'an Jiaotong University, Xi'an, Shaanxi 710054, P.R. China
}

Received September 29, 2019; Accepted April 17, 2020

DOI: $10.3892 / \mathrm{etm} .2021 .10758$

\begin{abstract}
Intervertebral disc degeneration (IDD) is a common disease with a high morbidity rate, which results in a significant deterioration in the quality of life of patients. MicroRNAs (miRNAs/miRs) are a class of endogenous small non-coding RNAs that influence target genes and serve critical roles in numerous biological processes. However, the role of miR-489-3p in lumbar disc degeneration is yet to be elucidated. In the present study, human NP cells were treated with $10 \mathrm{ng} / \mathrm{ml}$ lipopolysaccharide (LPS) for $24 \mathrm{~h}$ to investigate the role of miR-489-3p in IDD in an in vitro model. Reverse transcription-quantitative (RT-q)PCR was performed to determine the expression levels of miR-489-3p. Then, the TargetScan database was used to predict the potential binding sites between miR-489-3p and Toll-like receptor (TLR)4, and a dual-luciferase reporter assay was performed to verify the findings. Subsequently, RT-qPCR and western blotting were used to analyze the expression levels of TLR4. In addition, human nucleus pulposus (NP) cells were transfected with a miR-489-3p mimic and TLR4 overexpression plasmid to study the effects of miR-489-3p on LPS-induced human NP cells. Cell apoptosis and cell viability were also determined using flow cytometry and MTT assays, respectively. Finally, ELISAs were performed to analyze the levels of inflammatory factors. The expression levels of miR-489-3p were discovered to be downregulated in LPS-treated human NP cells. In addition, TLR4 was revealed to be a direct target gene of miR-489-3p, and its expression levels were upregulated in LPS-treated human NP cells. miR-489-3p was found to inhibit the LPS-induced decreases in cell viability and increases
\end{abstract}

Correspondence to: Mr. Bo Dong, Pain Rehabilitation Department of TCM Orthopedic Center, Honghui Hospital, Xi'an Jiaotong University, 555 Youyi East Road, Beilin, Xi'an, Shaanxi 710054, P.R. China

E-mail: dongbo181709@163.com

Key words: intervertebral disc degeneration, microRNA-489-3p, Toll-like receptor 4, human nucleus pulposus cells in apoptosis, and the concentration of inflammatory cytokines. Furthermore, miR-489-3p suppressed the LPS-induced decreases in extracellular matrix deposition via decreasing the expression levels of aggrecan and collagen type II in human NP cells. Finally, the results revealed that miR-489-3p inhibited the LPS-induced activation of the $\mathrm{NF}-\kappa \mathrm{B}$ signaling pathway in human NP cells. Conversely, all of the effects of miR-489-3p on LPS-induced human NP cells were reversed by the TLR4 overexpression plasmid. These findings suggested that miR-489-3p may represent a novel therapeutic target for the treatment of IDD.

\section{Introduction}

Intervertebral disc degeneration (IDD) is a degenerative disease of the spine originating from the intervertebral disc, which results in instability of the spine, disc herniation, spinal stenosis and cervical spondylosis (1). IDD is one of the most significant causes of musculoskeletal disability and it is a contributor to the increased motor dysfunction in the population (2). The incidence of lumbar disc degeneration is associated with age; an increase in age results in a higher incidence of lumbar disc degeneration (3). In addition, there are multiple other factors that are associated with IDD, such as obesity, bone density, smoking, diabetes, occupation and exercise (4-8). Lumbar disc degeneration significantly and adversely impacts the quality of life of patients (9). The combination of basic treatment, biomechanical adjustment and active exercise rehabilitation is a novel concept and represents a novel trend in the rehabilitative treatment of degenerative disc disease (10). Notably, previous studies have revealed that microRNAs (miRs/miRNAs) influence the occurrence and development of IDD (11).

At present, increasing evidence has indicated that miRNAs serve a crucial role in various types of disease (12), such as cancer (13), atherosclerosis (14) and cardiovascular diseases (15). miRNAs are a class of small non-coding RNAs that are 20-22 nucleotides in length (in contrast with mRNA-transcribed proteins) which inhibit the expression of multiple target genes by binding to their 3'untranslated region (3'UTR) (16-18). Previous studies have demonstrated that 
miR-25-3p regulates the proliferation and apoptosis of cancer cells in a variety of types of cancer. In addition, miR-25-3p was reported to be associated with the degradation of human nucleus pulposus (NP) cells (19); Lv et al (20) revealed that miR-146a may represent a novel target for IDD treatment; and Liu et al (21) demonstrated that miR-132 accelerated extracellular matrix (ECM) degradation in human NP cells via the targeting of the expression levels of growth differentiation factor 5. Moreover, miR-21 has been reported to promote ECM degradation by inhibiting autophagy via the PTEN/AKT/mTOR signaling pathway in human degenerated NP cells (22).

Previous research has also revealed that miR-489-3p serves an important role in secondary spinal cord injury (23). Other studies have also indicated the important roles of miR-489-3p in cell apoptosis, ECM and inflammation regulation (23-25). However, the role of miR-489-3p in IDD remains poorly understood.

Human NP cells secrete type II collagen, aggrecan and other components of the ECM, which serve a crucial role in maintaining intervertebral disc integrity $(26,27)$. During the progression of IDD, the excessive apoptosis of IVD cells and excessive degradation of ECM are observed (28). In addition, proinflammatory cytokines, such as tumor necrosis factor- $\alpha$ (TNF- $\alpha)$, interleukin (IL)-1 $\beta$ and IL-6, also serve important roles in IDD (29). Currently, lipopolysaccharide (LPS)-stimulated NP cells are widely used as an in vitro model for research into disc degeneration (20-22). It was hypothesized that miR-489-3p may be involved in IDD via regulating human NP cell apoptosis and ECM deposition. Thus, the present study aimed to investigate whether miR-489-3p influences IDD via the regulation of human NP cells.

\section{Materials and methods}

Cell culture and treatment. Human NP cells were obtained from Procell Life Science \& Technology Co., Ltd. (cat. no. CP-H097). The cells were cultured in DMEM/F12 medium (Invitrogen; Thermo Fisher Scientific, Inc.), supplemented with 10\% FBS (Invitrogen; Thermo Fisher Scientific, Inc.) and $1 \%(\mathrm{v} / \mathrm{v})$ penicillin-streptomycin (Gibco; Thermo Fisher Scientific, Inc.), and maintained in a humidified atmosphere at $5 \% \mathrm{CO}_{2}$ and $37^{\circ} \mathrm{C}$. When cells reached $80 \%$ confluency, the cells were subsequently treated with $10 \mathrm{ng} / \mathrm{ml}$ LPS (Sigma-Aldrich; Merck KGaA) at $37^{\circ} \mathrm{C}$ for $24 \mathrm{~h}$ to establish the IDD cell model in vitro. Cells without any treatment were used as the control.

Reverse transcription-quantitative $(R T-q) P C R$. Total RNA was extracted from human NP cells using TRIzol ${ }^{\circledR}$ reagent (Invitrogen; Thermo Fisher Scientific, Inc.), according to the manufacturer's protocol. All processes were carried out on ice. After extracting the RNA, the concentration of each sample was determined using an ultraviolet spectrophotometer. Total RNA was reverse transcribed into cDNA using HiScript III 1st Strand cDNA Synthesis Kit (Vazyme Biotech Co., Ltd.), according to the manufacturer's protocol. The reverse transcription reaction conditions were: $70^{\circ} \mathrm{C}$ for $5 \mathrm{~min}, 37^{\circ} \mathrm{C}$ for $5 \mathrm{~min}$ and $42^{\circ} \mathrm{C}$ for $60 \mathrm{~min}$. qPCR was subsequently performed using the ChamQ SYBR qPCR Master Mix (Vazyme Biotech
Co., Ltd.), according to the manufacturer's protocol. The following thermocycling conditions were used for the qPCR: Initial denaturation at $95^{\circ} \mathrm{C}$ for $3 \mathrm{~min}$; followed by 40 cycles of $95^{\circ} \mathrm{C}$ for $30 \mathrm{sec}, 56^{\circ} \mathrm{C}$ for $30 \mathrm{sec}$ and $72^{\circ} \mathrm{C}$ for $30 \mathrm{sec}$. The following primer sequences were used for the qPCR: miR-489-3p forward, 5'-GTGACATCACATATACGG-3' and reverse, 5'-GAACATGTCTGCGTATCTC-3'; TLR4 forward, 5'-CCTGACACCAGGAAGCTTGAA-3' and reverse, 5'-TCT GATCCATGCATTGGTAGGT-3'; aggrecan forward, 5'-CTA CCAGTGGATCGGCCTGAA-3' and reverse, 5'-CGTGCC AGATCATCACCACA-3'; collagen type II forward, 5'-GGC AATAGCAGGTTCACGTACA-3' and reverse, 5'-CGATAA CAGTCTTGCCCCACTT-3'; U6 forward, 5'-GCTTCGGCA GCACATATACTAAAAT-3' and reverse, 5'-CGCTTCACG AATTTGCGTGTCAT-3'; and GAPDH forward, 5'-CTTTGG TATCGTGGAAGGACTC-3' and reverse, 5'-GTAGAGGCA GGGATGATGTTCT-3'. Expression levels were calculated using the $2^{-\Delta \Delta \mathrm{Cq}}$ method (30) and GAPDH or U6 served as the internal control for normalization.

Western blotting. Total protein was extracted from cells using RIPA lysis buffer (Beyotime Institute of Biotechnology) according to the manufacturer's protocol. Total protein was quantified using a bicinchoninic acid assay kit (Pierce; Thermo Fisher Scientific, Inc.) and $30 \mu \mathrm{g}$ protein/lane was separated via $15 \%$ SDS-PAGE. The separated proteins were subsequently transferred onto a PVDF membrane (EMD Millipore) and blocked at room temperature using 5\% fat-free powdered milk dissolved in TBS-0.1\% Tween for $1.5 \mathrm{~h}$. The membranes were incubated with the following primary antibodies at $4{ }^{\circ} \mathrm{C}$ overnight: Anti-TLR4 antibody (cat. no. ab13556; 1:1,000; Abcam), anti-GAPDH (cat. no. ab181602; 1:1,000; Abcam), anti-aggrecan (cat. no. ab3778; 1:1,000; Abcam), anti-collagen type II (cat. no. ab34712; 1:1,000; Abcam), anti-p65 (cat. no. ab16502; 1:1,000; Abcam) and anti-phosphorylated (p)-p65 (cat. no. ab86299; 1:1,000; Abcam). Following the primary antibody incubation, the membranes were incubated with a horseradish peroxidase-conjugated secondary antibody (cat. no. ab7090; 1:2,000; Abcam) at room temperature for $2 \mathrm{~h}$. Protein bands were visualized using an enhanced chemiluminescence substrate (EMD Millipore) and analyzed using ImageJ version 2.0 software (National Institutes of Health). The expression levels were normalized to GAPDH.

Dual-luciferase reporter assay. Bioinformatics analysis using TargetScan 7.2 (http://www.targetscan.org/vert_72/) was performed to determine the binding sites between miR-489-3p and TLR4. The wild-type (WT) or mutant (MUT) 3'UTR of TLR4 was cloned into the pmiRGLO vector (Promega Corporation) and the recombinant plasmids were acquired using an EndoFree Plasmid Maxi kit (Vazyme Biotech Co., Ltd.). To point-mutate the miR-489-3p binding domain in the 3'UTR of TLR4, a QuikChange Site-Directed Mutagenesis kit (Stratagene; Agilent Technologies, Inc.) was used according to the manufacturer's instructions. Cells were seeded into 24-well plates at a density of $5 \times 10^{4}$ cells/well and co-transfected with a miR-489-3p mimic or mimic control and the MUT or WT 3'UTR of TLR4 using Fugene transfection reagent (Promega Corporation) according to the manufacturer's protocol, together with the Renilla luciferase pRL-TK vector (Promega 
Corporation) as a control. Following transfection at $37^{\circ} \mathrm{C}$ for 48 h, firefly and Renilla luciferase activities were determined using a Dual-Luciferase Reporter assay system (Promega Corporation) according to the manufacturer's protocol. Firefly luciferase activity was normalized to Renilla luciferase activity.

Cell transfection. Human NP cells $\left(5 \times 10^{4}\right.$ cells per well) were transiently transfected with a $100 \mathrm{nM}$ mimic control (5'-UUG UCCGAACGUGUCACGUTT-3'; Suzhou GenePharma Co., Ltd.), 100 nM miR-489-3p mimic (5'-GUGACAUCACAU AUACGGCAGC-3'; Suzhou GenePharma Co., Ltd.), $1 \mu \mathrm{g}$ Control CRISPR Activation Plasmid (cat. no. sc-437275; Santa Cruz Biotechnology, Inc.), $1 \mu \mathrm{g}$ TLR4 CRISPR Activation Plasmid (cat. no. sc-400068-ACT; Santa Cruz Biotechnology, Inc.), $100 \mathrm{nM}$ miR-489-3p mimic $+1 \mu \mathrm{g}$ control-plasmid or $100 \mathrm{nM}$ miR-489-3p mimic $+1 \mu \mathrm{g}$ TLR4-plasmid at $37^{\circ} \mathrm{C}$ for $24 \mathrm{~h}$ using Fugene transfection reagent (Promega Corporation) according to the manufacturer's protocol. The transfection efficiency was detected using a RT-qPCR assay. Following $24 \mathrm{~h}$ of cell transfection, the cells were treated with $10 \mathrm{ng} / \mathrm{ml}$ LPS at $37^{\circ} \mathrm{C}$ for $24 \mathrm{~h}$ and then the cells were subjected to subsequent experiments (Fig. S1).

MTT assay. Cell viability was determined via an MTT assay. Briefly, transfected human NP cells were treated with $10 \mathrm{ng} / \mathrm{ml}$ LPS at $37^{\circ} \mathrm{C}$ for $24 \mathrm{~h}$ and then cells were plated in 96-well plates at a density of $5 \times 10^{3}$ cells/well. Following $48 \mathrm{~h}$ of incubation at $37^{\circ} \mathrm{C}, 20 \mu \mathrm{l}$ MTT reagent (Beyotime Institute of Biotechnology) was added into each well and incubated for $4 \mathrm{~h}$ at $37^{\circ} \mathrm{C}$. Subsequently, $150 \mu \mathrm{l} \mathrm{DMSO}$ was added into each well and the solution was agitated at $37^{\circ} \mathrm{C}$ for $15 \mathrm{~min}$. The optical density values were measured at $570 \mathrm{~nm}$ using a microplate reader.

Flow cytometric analysis of apoptosis. Cell apoptosis was analyzed using an Annexin V-FITC Apoptosis Detection kit (Beyotime Institute of Biotechnology) according to the manufacturer's protocol. Briefly, the cells $\left(1 \times 10^{6}\right)$ were washed with $1 \mathrm{X}$ PBS three times, centrifuged at $4^{\circ} \mathrm{C}$ for $5 \mathrm{~min}$ at $1,000 \mathrm{x} \mathrm{g}$, and trypsinized into single cell suspensions with $500 \mu 1$ buffer (Beyotime). The cells were stained with $5 \mu$ l Annexin V-FITC and $5 \mu \mathrm{l}$ propidium iodide at room temperature for 15 min. Apoptotic cells were subsequently analyzed using BD FACSCalibur flow cytometer (BD Biosciences) and analyzed using FlowJo 7.6.1 software (FlowJo LLC).

ELISAs. Following $24 \mathrm{~h}$ of cell transfection, NP cells were treated with $10 \mathrm{ng} / \mathrm{ml} \mathrm{LPS}$, and the supernatants were subsequently harvested through centrifugation at $500 \mathrm{x}$ g at $4^{\circ} \mathrm{C}$ for 5 min. Subsequently, specific ELISA kits (Beyotime Institute of Biotechnology) were used, according to the manufacturers' protocol, to determine the concentrations of TNF- $\alpha$ (cat. no. PT518), IL-1 $\beta$ (cat. no. PI305) and IL-6 (cat. no. PI330) in the cell culture supernatant from the different groups.

Statistical analysis. Statistical analysis was performed using GraphPad Prism 6.0 software (GraphPad Software, Inc.); each experiment was performed in triplicate and all data are presented as the mean \pm SD. Statistical differences between

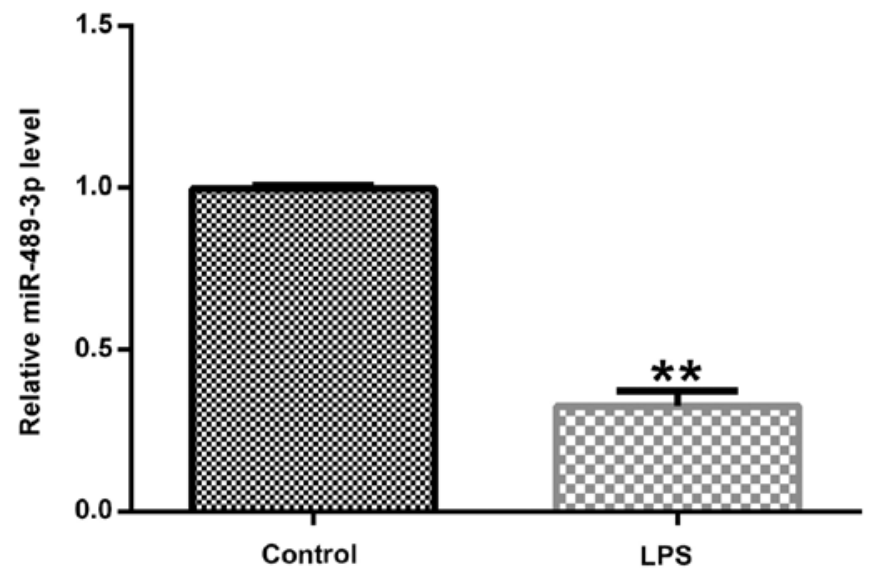

Figure 1. miR-489-3p expression levels are downregulated in an intervertebral disc degeneration in vitro cell model. Reverse transcription-quantitative PCR was used to analyze the expression levels of miR-489-3p in human NP cells treated with $10 \mathrm{ng} / \mathrm{ml}$ LPS for $24 \mathrm{~h}$. miR, microRNA; LPS, lipopolysaccharide. ${ }^{* *} \mathrm{P}<0.01$ vs. control.

two groups were determined using a unpaired Student's t-test, whereas an one-way ANOVA followed by Tukey's post hoc test was used to analyze the statistical differences between multiple groups. $\mathrm{P}<0.05$ was considered to indicate a statistically significant difference.

\section{Results}

Expression levels of miR-489-3p in human NP cells. To investigate the effects of miR-489-3p on an IDD model in vitro, RT-qPCR was performed to detect the expression levels of miR-489-3p. The expression levels of miR-489-3p were significantly downregulated in the LPS-treated group compared with the control group (Fig. 1).

TLR4 is a direct target gene of miR-489-3p. Subsequently, to determine the interaction between miRNA and its target genes, the TargetScan tool was used to predict the target genes of miR-489-3p; it was revealed that the TLR4 3'UTR contained a putative site that was partially complementary to miR-489-3p (Fig. 2A). Furthermore, the dual-luciferase reporter assay was used to determine whether miR-489-3p interacted directly with the target gene TLR4. The reporter containing the TLR4-WT 3'UTR exhibited significantly decreased relative luciferase activity in the human NP cells co-transfected with the miR-489-3p mimic compared with the mimic control (Fig. 2B). Taken together, the current results indicated that TLR4 may be a direct target gene of miR-489-3p.

Subsequently, RT-qPCR and western blotting assays were used to determine the expression levels of TLR4. The results of these assays revealed that TLR4 expression levels were upregulated in the LPS-treated group compared with control group at both the mRNA and protein level (Fig. 3A and B).

TLR4 is negatively regulated by miR-489-3p in human NP cells. Human NP cells were transfected with either a mimic control or miR-489-3p mimic. RT-qPCR revealed that compared with the mimic control group, the miR-489-3p mimic significantly increased the expression levels of miR-489-3p in human 
A

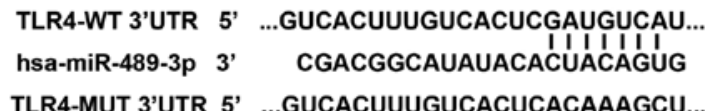

B

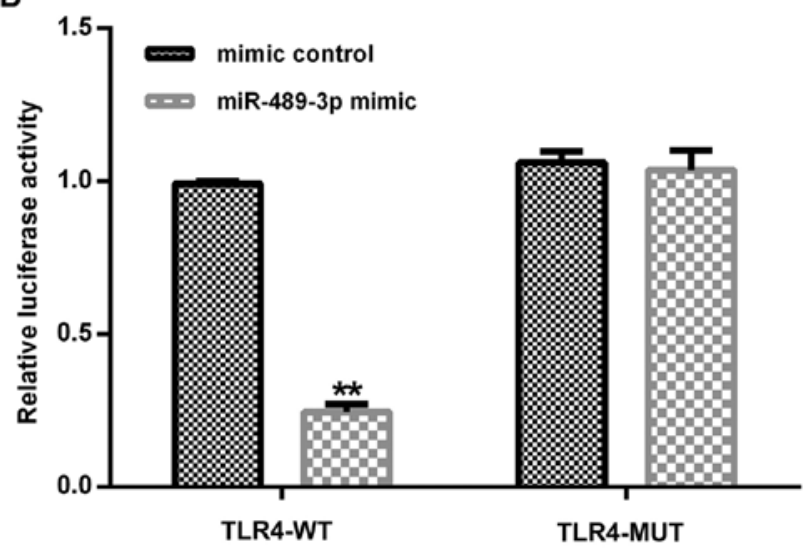

Figure 2. TLR4 is a direct target gene of miR-489-3p. (A) TargetScan was used to predict the TLR4 3'UTR binding site for miR-489-3p. (B) miR-489-3p mimic or mimic control and WT or MUT TLR4 3'UTR reporter were co-transfected into human nucleus pulposus cells. A dual-luciferase reporter activity was used to determine the relative luciferase activity. miR, microRNA; TLR4, Toll-like receptor 4; 3'UTR, 3'untranslated region; WT, wild-type; MUT, mutant. ${ }^{* *} \mathrm{P}<0.01$ vs. mimic control.

NP cells (Fig. 4A). Subsequently, the cells were transfected with either the control- or TLR4-plasmid; the results indicated that compared with the control-plasmid group, TLR4 mRNA expression levels were significantly upregulated in the TLR4-plasmid group (Fig. 4B). Then, the effect of miR-489-3p on TLR4 expression levels was examined. Human NP cells were transfected with either a miR-489-3p mimic + control-plasmid or miR-489-3p mimic + TLR4-plasmid. It was demonstrated that compared with the mimic control group, the miR-489-3p mimic significantly decreased the expression levels of TLR4 in human NP cells, which was partially restored following the co-transfection with the TLR4-plasmid (Fig. 4C and D).

miR-489-3p promotes cell viability and inhibits apoptosis in LPS-induced human NP cells. The effect of miR-489-3p on cell viability and apoptosis in LPS-induced human NP cells was examined. Compared with the control group, LPS treatment significantly inhibited NP cell viability and induced apoptosis (Fig. 5A-C). However, compared with the LPS-treated group, the miR-489-3p mimic group exhibited significantly increased NP cell viability (Fig. 5A) and decreased cell apoptosis (Fig. 5B and C), which was partially reversed following the co-transfection with the TLR4-plasmid.

miR-489-3p inhibits the levels of inflammatory cytokines in LPS-induced human NP cells. To determine the effect of miR-489-3p on the levels of inflammatory factors in LPS-induced human NP cells, ELISAs were performed to analyze the expression levels of TNF- $\alpha$, IL- $1 \beta$ and IL- 6 . The results indicated that compared with the control group, LPS treatment significantly increased the secretion of TNF- $\alpha$, IL-1 $\beta$ and IL-6 in human NP cells (Fig. 6A-C). Notably, the transfection with the miR-489-3p mimic significantly reduced these LPS-induced increases in the expression levels of TNF- $\alpha$, IL-1 $\beta$ and IL-6 (Fig. 6A-C), which were significantly restored following transfection with the TLR4-plasmid.

miR-489-3p inhibits ECM breakdown in LPS-induced human $N P$ cells. RT-qPCR and western blot assays were conducted to analyze the expression levels of ECM-associated proteins. Compared with the control group, LPS treatment significantly reduced the expression levels of aggrecan and collagen type II in human NP cells at the protein (Fig. 7A-C) and mRNA level (Fig. 7D and E). Moreover, compared with the LPS-treated group, the miR-489-3p mimic significantly increased the expression levels of aggrecan and collagen type II in human NP cells, and this effect was partially reversed following the co-transfection with the TLR4-plasmid.

miR-489-3p inhibits the activation of the $N F-\kappa B$ signaling pathway in LPS-induced human NP cells. Finally, the specific mechanism underlying the influence of miR-489-3p in IDD was investigated. Western blotting revealed that LPS treatment significantly increased the protein expression levels of p-p65 and the ratio of $\mathrm{p}-\mathrm{p} 65 / \mathrm{p} 65$ in human NP cells compared with the control group (Fig. 8A and B). However, the miR-489-3p mimic decreased the protein expression levels of p-p65 (Fig. 8A) and the ratio of p-p65/p65 (Fig. 8B); this effect was significantly restored following co-transfection with the TLR4-plasmid.

\section{Discussion}

In the present study, human NP cells were treated with LPS to establish an IDD model in vitro and it was revealed that TLR4 is a direct target gene of miR-489-3p. Notably, miR-489-3p expression levels were discovered to be downregulated in LPS-treated human NP cells and TLR4 expression levels were observed to be negatively associated with miR-489-3p expression levels. Subsequently, NP cells were transfected with a miR-489-3p mimic and TLR4 overexpression plasmid to study the effect of miR-489-3p on human NP cells. The results indicated that miR-489-3p suppressed the LPS-induced decreases in cell viability and increases in cell apoptosis in human NP cells. Moreover, miR-489-3p decreased the expression levels of the inflammatory cytokines, TNF- $\alpha$, IL- $1 \beta$ and IL- 6 , and inhibited the degradation of the ECM (evidenced by increased expression levels of the ECM proteins), in LPS-induced human NP cells. Finally, it was also revealed that miR-489-3p decreased the expression levels of $\mathrm{p}-\mathrm{p} 65$, which is associated with the NF- $\kappa B$ signaling pathway (31).

IDD is the primary cause of lower back pain and it is a medical condition that places a heavy burden on the global medical system, resulting in significant socioeconomic consequences (32-34). At present, due to both professional and personal factors, the incidence of IDD is increasing, particularly in China (35). Currently, rehabilitation is important following lumbar spine fusion surgery for degenerative diseases and it is critical for the healing of degenerative diseases (36).

Previous studies have indicated that miRNAs are regulators of gene expression and serve important roles in the prevention and treatment of IDD $(37,38)$. It has been reported 


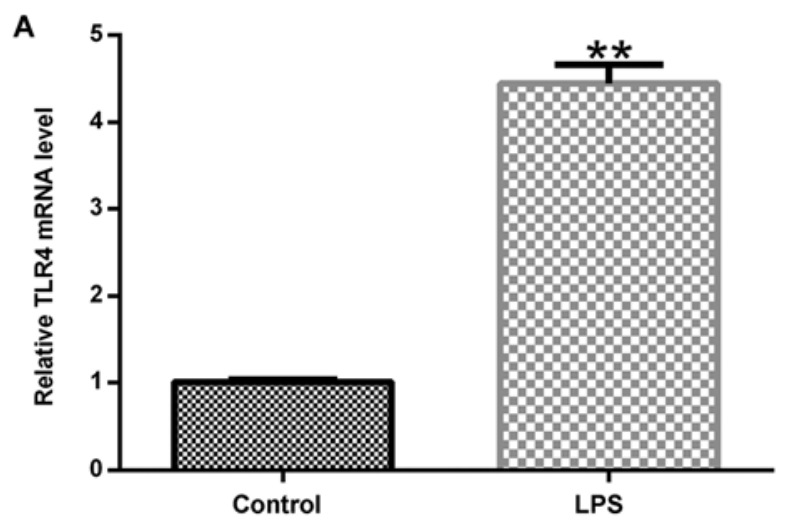

B

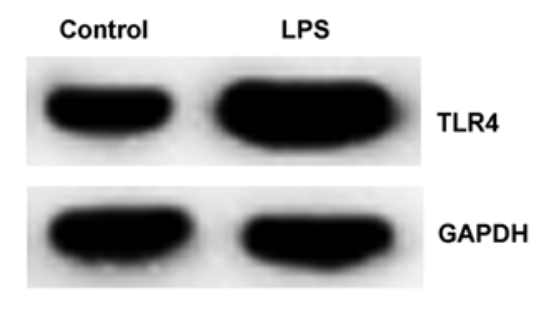

Figure 3. TLR4 expression levels are upregulated in an intervertebral disc degeneration in vitro cell model. (A) Reverse transcription-quantitative PCR and (B) western blotting were used to analyze the expression levels of TLR4 at the mRNA and protein level, respectively. TLR4, Toll-like receptor 4; LPS, lipopolysaccharide. ${ }^{* *} \mathrm{P}<0.01$ vs. Control.
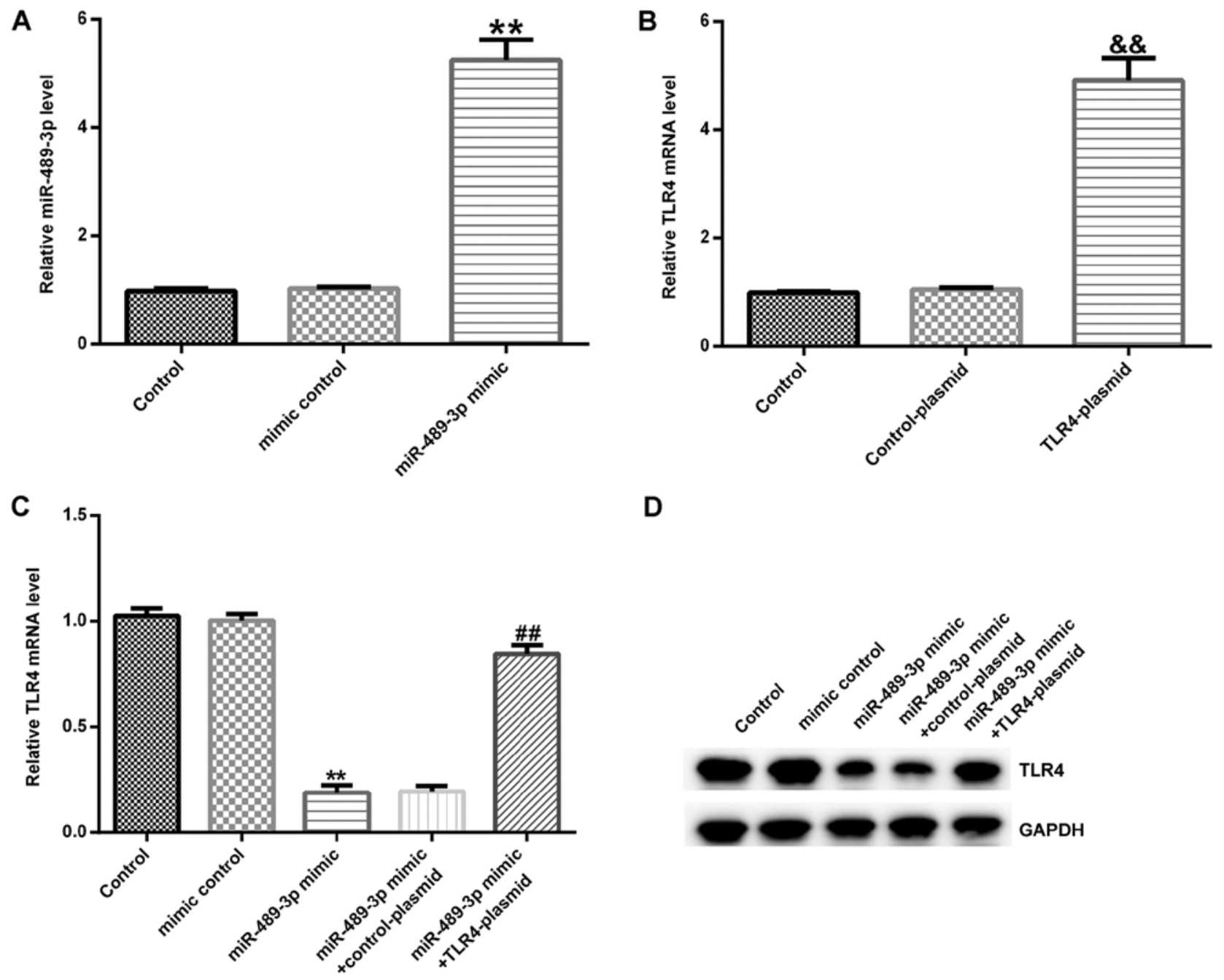

D

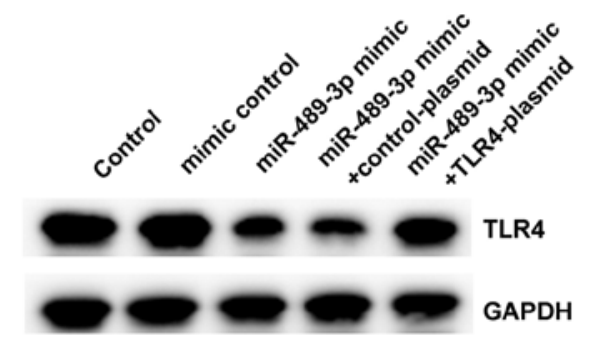

Figure 4. Transfection efficiency of TLR4 and miR-489-3p in human NP cells. RT-qPCR was used to determine the expression levels of (A) miR-489-3p and (B) TLR4 following transfection of the miR-489-3p mimic or TLR4-plasmid, respectively. (C) RT-qPCR and (D) western blotting was used to analyze the expression levels of TLR4 at the mRNA and protein level, respectively. TLR4, Toll-like receptor 4; NP, nucleus pulposus; RT-qPCR, reverse transcription-quantitative PCR; miR, microRNA. ${ }^{* *} \mathrm{P}<0.01$ vs. mimic control; ${ }^{\& \&} \mathrm{P}<0.01$ vs. control-plasmid; ${ }^{\# \#} \mathrm{P}<0.01$ vs. miR-489-3p mimic +control-plasmid.

that several miRNAs were found to be dysregulated in IDD, including miR-21, -10b, -155 and -27 (37,39-41), whereas miR-200c was discovered to be upregulated in degenerative NP tissues (42). In the present study, miR-489-3p was demonstrated to be downregulated in LPS-treated human NP cells. miR-489 expression levels were decreased in numerous types of cancer tissue, such as gastric cancer (43) and breast cancer (44). In addition, miR-489 was revealed to influence 
A

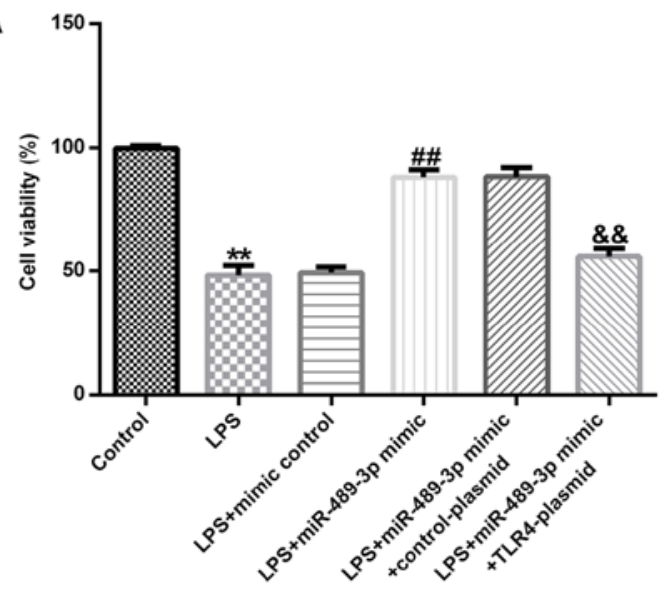

B

Control

LPS
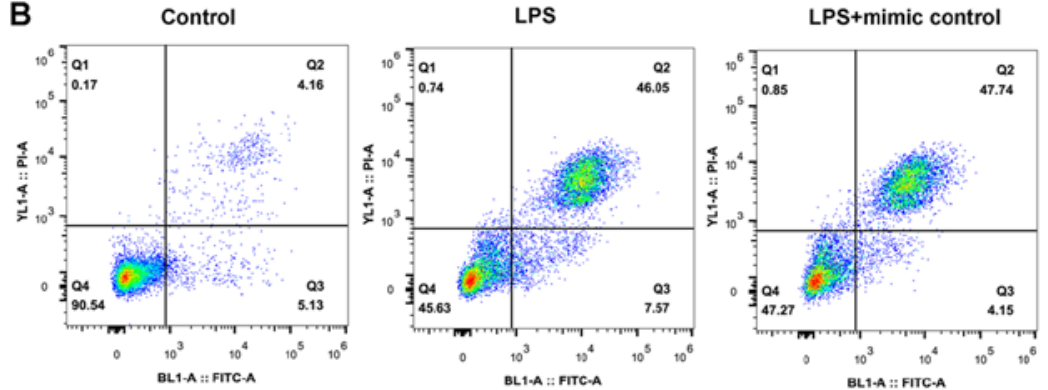

C
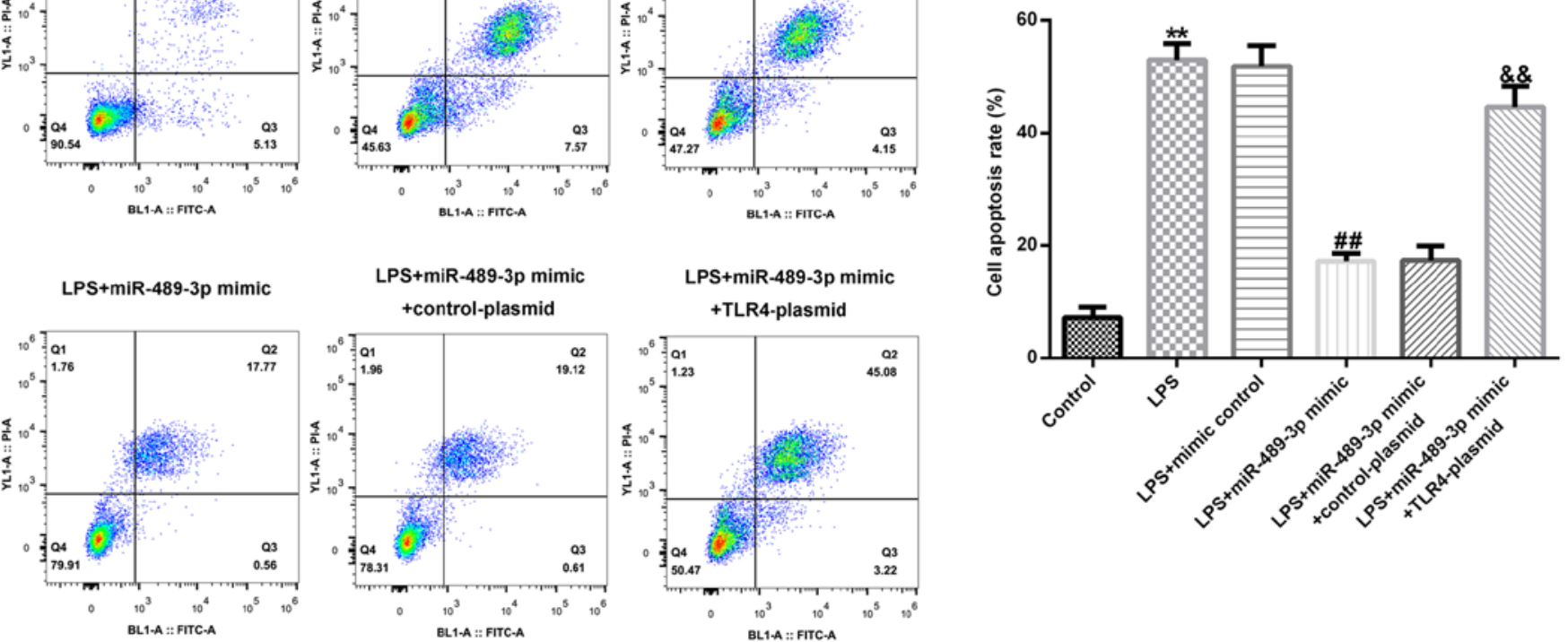

Figure 5. miR-489-3p enhances the cell viability and reduces the apoptotic rate in LPS-induced human NP cells. (A) MTT assay was used to determine the cell viability of human NP cells transfected with mimic control, miR-489-3p mimic, miR-489-3p mimic + control-plasmid or miR-489-3p mimic + TLR4-plasmid for $24 \mathrm{~h}$ and treated with $10 \mathrm{ng} / \mathrm{ml} \mathrm{LPS}$ for $24 \mathrm{~h}$. (B) Flow cytometry was used to determine the apoptotic rate of cells transfected with mimic control, miR-489-3p mimic, miR-489-3p mimic + control-plasmid or miR-489-3p mimic + TLR4-plasmid for $24 \mathrm{~h}$ and then treated with $10 \mathrm{ng} / \mathrm{ml}$ LPS for $24 \mathrm{~h}$. (C) apoptotic rate of cells was calculated and presented. TLR4, Toll-like receptor 4; miR, microRNA; NP, nucleus pulposus; LPS, lipopolysaccharide; PI, propidium iodide. ${ }^{* *} \mathrm{P}<0.01$ vs. Control; ${ }^{\# \#} \mathrm{P}<0.01$ vs. $L P S+$ mimic control; ${ }^{\&} \mathrm{P}<0.01$ vs. LPS+miR-489-3p mimic+control-plasmid.
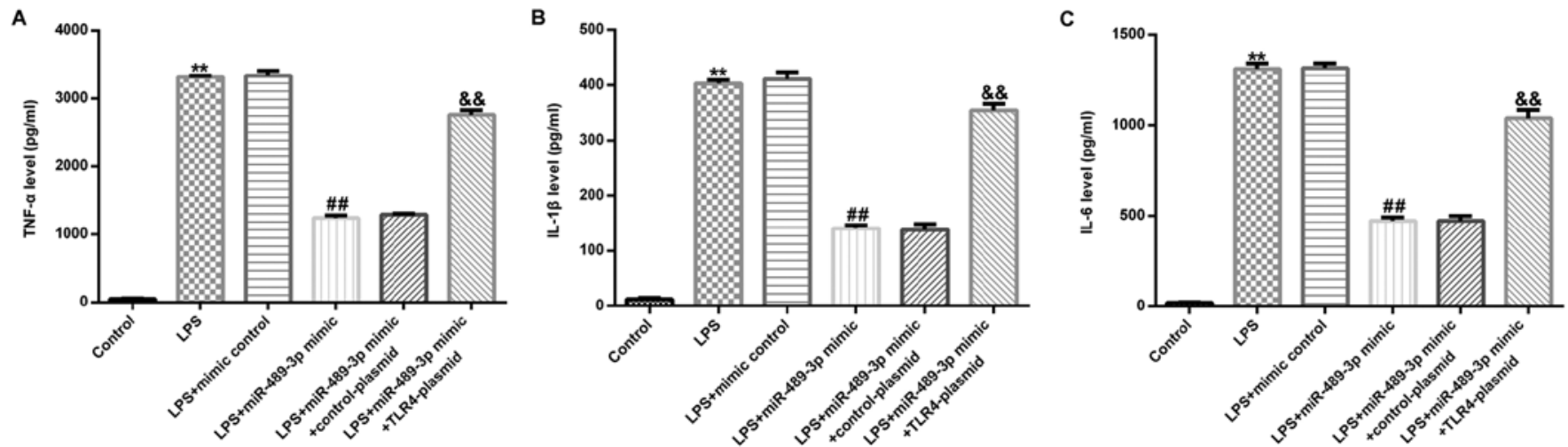

Figure 6. miR-489-3p suppresses the secretion of TNF- $\alpha$, IL-1 $\beta$ and IL-6 in LPS-induced human NP cells. Human NP cells were transfected with the mimic control, miR-489-3p mimic, miR-489-3p mimic + control-plasmid or miR-489-3p mimic + TLR4-plasmid for $24 \mathrm{~h}$ and treated with $10 \mathrm{ng} / \mathrm{ml} \mathrm{LPS} \mathrm{for} 24 \mathrm{~h}$. ELISAs were used to analyze the expression levels of (A) TNF- $\alpha$, (B) IL-1 $\beta$ and (C) IL-6 in human NP cells. TLR4, Toll-like receptor 4; miR, microRNA; $\mathrm{NP}$, nucleus pulposus; LPS, lipopolysaccharide; IL, interleukin; TNF, tumor necrosis factor. ${ }^{* *} \mathrm{P}<0.01$ vs. Control; ${ }^{\# \#} \mathrm{P}<0.01$ vs. $L P S+$ mimic control; ${ }^{\& \&} \mathrm{P}<0.01$ vs. $\mathrm{LPS}+\mathrm{miR}-489-3 \mathrm{p}$ mimic+control-plasmid. 
A

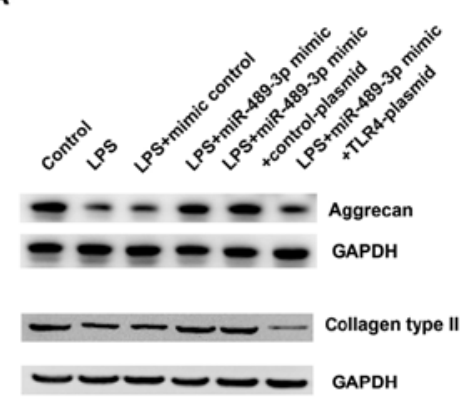

D

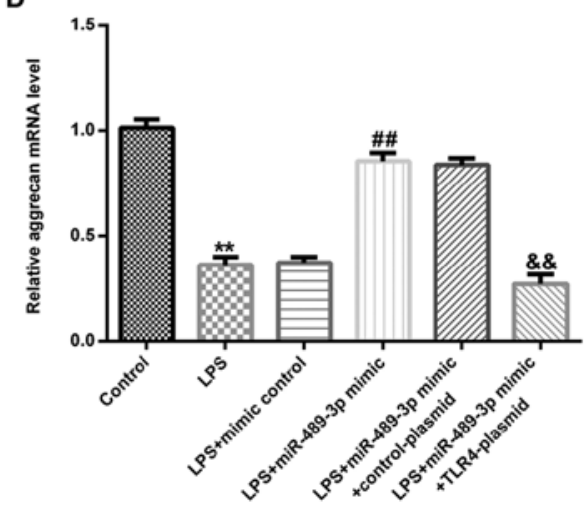

B

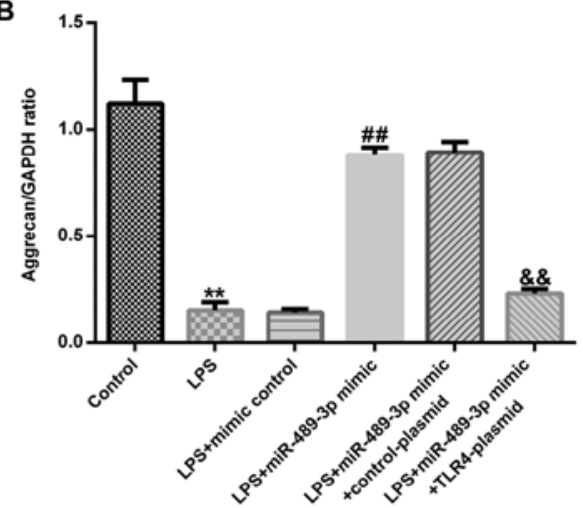

E

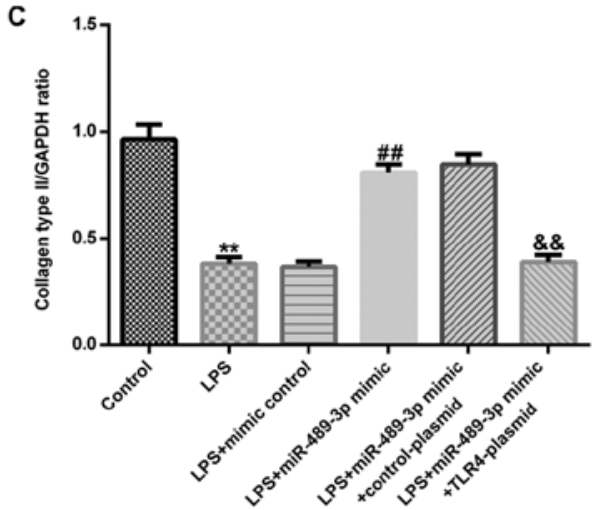

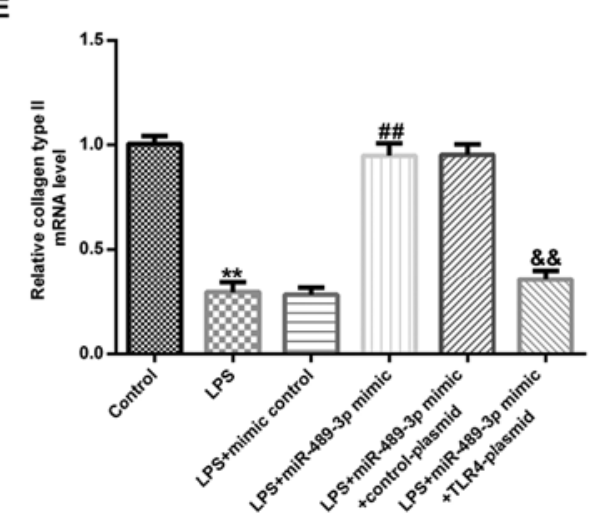

Figure 7. miR-489-3p inhibits extracellular matrix degradation in LPS-induced human NP cells. Human NP cells were transfected with mimic control, miR-489-3p mimic, miR-489-3p mimic + control-plasmid or miR-489-3p mimic + TLR4-plasmid for $24 \mathrm{~h}$ and treated with $10 \mathrm{ng} / \mathrm{ml} \mathrm{LPS}$ for $24 \mathrm{~h}$. (A) Western blotting was used to analyze the expression levels of aggrecan and collagen type II at the protein level. The expression levels of (B) aggrecan and (C) collagen type II were semi-quantified from the blot presented in part A. Reverse transcription-quantitative PCR was used to analyze the expression levels of (D) aggrecan and (E) collagen type II at the mRNA level. TLR4, Toll-like receptor 4; miR, microRNA; NP, nucleus pulposus; LPS, lipopolysaccharide. ${ }^{* *} \mathrm{P}<0.01$ vs. Control; ${ }^{\# \#} \mathrm{P}<0.01$ vs. $L P S+$ mimic control; ${ }^{\& \&} \mathrm{P}<0.01$ vs. $\mathrm{LPS}+\mathrm{miR}-489-3 \mathrm{p}$ mimic+control-plasmid.

A

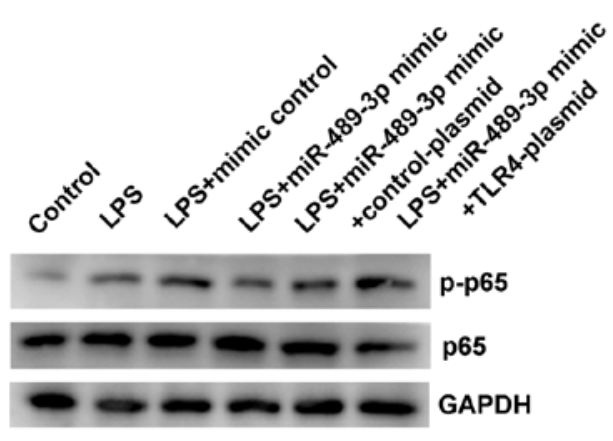

B

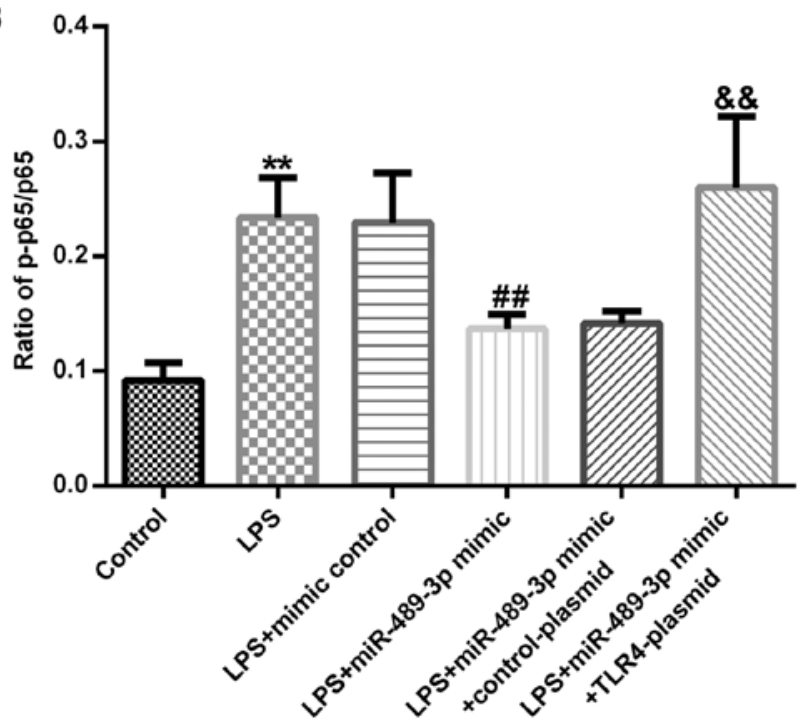

Figure 8. Association between miR-489-3p and NF- $\mathrm{BB}$ signaling pathway in LPS-induced human NP cells. Human NP cells were transfected with mimic control, miR-489-3p mimic, miR-489-3p mimic + control-plasmid or miR-489-3p mimic + TLR4-plasmid for $24 \mathrm{~h}$ and treated with $10 \mathrm{ng} / \mathrm{ml} \mathrm{LPS}$ for $24 \mathrm{~h}$. (A) Western blotting was used to analyze the expression levels of p-p65 and p65. (B) Ratio of p-p65/p65 was semi-quantified from the blot presented in part A. TLR4, Toll-like receptor 4; miR, microRNA; NP, nucleus pulposus; $\mathrm{p}$-, phosphorylated; LPS, lipopolysaccharide. ${ }^{* *} \mathrm{P}<0.01 \mathrm{vs}$. Control; ${ }^{\# \#} \mathrm{P}<0.01 \mathrm{vs}$. $L P S+$ mimic control; \& ${ }^{\&}<0.01$ vs. LPS+miR-489-3p mimic+control-plasmid.

multiple pathological processes, such as proliferation, apoptosis, invasiveness and the metastasis of tumor cells (45). It has also been reported that the miR-489-3p sequence shares high homology to the miR-489 sequence. 
The majority of miRNAs serve their biological function by complementarily binding their target gene (46). In the current study, it was discovered that TLR4 was a target gene of miR-489-3p. TLR4 is an innate and adaptive immune cell receptor (47), which serves a vital role in the inflammatory response (48). Notably, Yang et al (47) also indicated that TLR4 may be a target gene of miR-760. In addition, TLR4 has been reported to be regulated by several miRNAs, including miR-708-5p (49), miR-106a (50) and miR-20a (51). Wu et al (52) reported that the primary pathological changes in IDD were NP apoptosis and the significant degradation of the ECM. miRNAs have been identified to regulate cell apoptosis and ECM protein expression (53-56). Notably, several studies have demonstrated that miRNAs influence the occurrence and development of IDD by regulating the apoptosis and ECM deposition of NP cells (20-22,57,58). For example, miR-132 was revealed to promote matrix degradation in IDD via increased ECM catabolic factors (matrix metalloproteinase 13 and $\mathrm{A}$ disintegrin and metalloproteinase with thrombospondin motifs 4), and decreased anabolic proteins (type II collagen and aggrecan) in NP cells (21). In other previous studies, miR-21 was also demonstrated to contribute to type II collagen and aggrecan catabolism in human NP cells (22); miR-145 suppressed apoptosis and promoted ECM synthesis in NP cells (57); and miR-499a-5p was revealed to suppress the apoptosis of human NP cells and inhibit the degradation of the ECM via targeting the transcription factor SOX-4 (58). In the present study it was determined that miR-489-3p suppressed the LPS-induced decreases in cell viability and the increase in cell apoptosis in human NP cells. However, the cell viability was analyzed following the treatment of human NP cells with $10 \mathrm{ng} / \mathrm{ml}$ LPS for $24 \mathrm{~h}$; this was a limitation of the present study and the study protocol could be improved by subjecting the cells to longer term viability assays. In addition, the results indicated that miR-489-3p may inhibit the LPS-induced degradation of the ECM in human NP cells.

Altogether, the findings of the present study suggest that miR-489-3p may regulate the LPS-induced NP cell inflammatory response, apoptosis and ECM-related protein expression; however, their interaction and relationship with each other requires further investigation in the future. Furthermore, the present study did not use a miR-489-3p mimic control + TLR4-plasmid + LPS group, which is also represents a limitation. Thus, the targeting of miR-489-3p may represent a promising therapeutic strategy and the current study may have identified novel therapeutic targets for the development of treatments for IDD.

In conclusion, miR-489-3p was discovered to inhibit the LPS-induced decreases in cell viability and increases in apoptosis, the inflammatory response and ECM degradation in human NP cells via the suppression of the NF- $\kappa B$ signaling pathway via the targeting of TLR4. Therefore, miR-489-3p may represent a potential target for IDD treatment. However, the current study is only a preliminary study of the role of miR-489-3p in IDD. To clarify the mechanism underlying the role of miR-489-3p in IDD, numerous additional in-depth experiments are required. For example, the role of TLR4-plasmid in LPS-treated NP cells should be studied and investigations into the role of the miR-489-3p/TLR4 axis in IDD in vivo should be performed. In addition, the expression levels of miR-489-3p/TLR4 in patients with IDD and the association between miR-489-3p and TLR4 expression levels and the clinicopathological characteristics of patients with IDD should be investigated; our future studies aim to cover some of these investigations.

\section{Acknowledgements}

Not applicable.

\section{Funding}

No funding was received.

\section{Availability of data and materials}

The datasets used and/or analyzed during the current study are available from the corresponding author on reasonable request.

\section{Authors' contributions}

LD contributed to the design of the study, data collection, statistical analysis, data interpretation and manuscript preparation. BD contributed to the data collection, statistical analysis and manuscript preparation. All authors read and approved the final manuscript.

\section{Ethics approval and consent to participate}

Not applicable.

\section{Patient consent for publication}

Not applicable.

\section{Competing interests}

The authors declare that they have no competing interests.

\section{References}

1. Kadow T, Sowa G, Vo N and Kang JD: Molecular basis of intervertebral disc degeneration and herniations: What are the important translational questions? Clin Orthop Relat Res 473: 1903-1912, 2015.

2. Tang P, Gu JM, Xie ZA, Gu Y, Jie ZW, Huang KM, Wang JY, Fan SW, Jiang XS and Hu ZJ: Honokiol alleviates the degeneration of intervertebral disc via suppressing the activation of TXNIP-NLRP3 inflammasome signal pathway. Free Radic Biol Med 120: 368-379, 2018.

3. Powell MC, Wilson M, Szypryt P, Symonds EM and Worthington BS: Prevalence of lumbar disc degeneration observed by magnetic resonance in symptomless women. Lancet 2: 1366-1367, 1986.

4. Hangai M, Kaneoka K, Kuno S, Hinotsu S, Sakane M, Mamizuka N, Sakai S and Ochiai N: Factors associated with lumbar intervertebral disc degeneration in the elderly. Spine J 8: 732-740, 2008.

5. Liuke M, Solovieva S, Lamminen A, Luoma K, Leino-Arjas P, Luukkonen R and Riihimäki H: Disc degeneration of the lumbar spine in relation to overweight. Int J Obes (Lond) 29: 903-908, 2005.

6. Oda H, Matsuzaki H, Tokuhashi Y, Wakabayashi K, Uematsu Y and Iwahashi $\mathrm{M}$ : Degeneration of intervertebral discs due to smoking: Experimental assessment in a rat-smoking model. J Orthop Sci 9: 135-141, 2004. 
7. Jhawar BS, Fuchs CS, Colditz GA and Stampfer MJ: Cardiovascular risk factors for physician-diagnosed lumbar disc herniation. Spine J 6: 684-691, 2006.

8. Kauppila LI: Atherosclerosis and disc degeneration/low-back pain-a systematic review. Eur J Vasc Endovasc Surg 37: 661-670, 2009.

9. Enercan M, Kahraman S, Cobanoglu M, Yilar S, Gokcen BH Karadereler S, Mutlu A, Ulusoy LO, Ozturk C, Erturer E, et al: Selective thoracic fusion provides similar health-related quality of life but can cause more lumbar disc and facet joint degeneration: A comparison of adolescent idiopathic scoliosis patients with normal population 10 years after surgery. Spine Deform 3: 469-475, 2015.

10. Canbulat N, Oktenoglu T, Ataker Y, Sasani M, Ercelen O, Cerezci O, Suzer T and Ozer AF: A rehabilitation protocol for patients with lumbar degenerative disc disease treated with posterior transpedicular dynamic stabilization. Turk Neurosurg 27: 426-435, 2017.

11. Ji ML, Jiang H, Zhang XJ, Shi PL, Li C, Wu H, Wu XT, Wang YT, Wang $\mathrm{C}$ and $\mathrm{Lu} \mathrm{J}$ : Preclinical development of a microRNA-based therapy for intervertebral disc degeneration. Nat Commun 9: 5051,2018

12. Lv K: Expression profiles of miRNAs in polarized macrophages. Int J Mol Med 31: 797-802, 2013.

13. Chen X, Slack FJ and Zhao H: Joint analysis of expression profiles from multiple cancers improves the identification of microRNA-gene interactions. Bioinformatics 29: 2137-2145, 2013.

14. Wei Y, Nazari-Jahantigh M, Chan L, Zhu M, Heyll K, Corbalán-Campos J, Hartmann P, Thiemann A, Weber C and Schober A: The microRNA-342-5p fosters inflammatory macrophage activation through an akt1- and microRNA-155-depend-ent pathway during atherosclerosis. Circulation 127: 1609-1619,2013.

15. Ono K, Kuwabara Y and Han J: MicroRNAs and cardiovascular diseases. FEBS J 278: 1619-1633, 2011.

16. Ro S, Park C, Young D, Sanders KM and Yan W: Tissue-dependent paired expression of miRNAs. Nucleic Acids Res 35: 5944-5953 2007.

17. Mallory AC and Vaucheret H: MicroRNAs: Something important between the genes. Curr Opin Plant Biol 7: 120-125, 2004

18. Garzon R, Calin GA and Croce CM: MicroRNAs in cancer. Annu Rev Med 60: 167-179, 2009.

19. Xu JY, Yang LL, Ma C, Huang YL, Zhu GX and Chen QL: MiR-25-3p attenuates the proliferation of tongue squamous cel carcinoma cell line Tca8113. Asian Pac J Trop Med 6: 743-747, 2013.

20. Lv F, Huang Y, Lv W, Yang L, Li F, Fan J and Sun J: MicroRNA-146a ameliorates inflammation via TRAF6/NF- $\mathrm{KB}$ pathway in intervertebral disc cells. Med Sci Monit 23: 659-664, 2017.

21. Liu W, Xia P, Feng J, Kang L, Huang M, Wang K, Song Y, Li S, Wu X, Yang S and Yang C: MicroRNA-132 upregulation promotes matrix degradation in intervertebral disc degeneration. Exp Cell Res 359: 39-49, 2017.

22. Wang WJ, Yang W, Ouyang ZH, Xue JB, Li XL, Zhang J, He WS Chen WK, Yan YG and Wang C: MiR-21 promotes ECM degradation through inhibiting autophagy via the PTEN/akt/mTOR signaling pathway in human degenerated NP cells. Biomed Pharmacother 99: 725-734, 2018

23. Jiang R, Zhang C, Gu R and Wu H: MicroRNA-489-3p inhibits neurite growth by regulating PI3K/AKT pathway in spinal cord injury. Pharmazie 72: 272-278, 2017.

24. Wu Q, Han L, Yan W, Ji X, Han R, Yang J, Yuan J and Ni C: miR-489 inhibits silica-induced pulmonary fibrosis by targeting MyD88 and Smad3 and is negatively regulated by lncRNA CHRF. Sci Rep 6: 30921, 2016.

25. Wiese CB, Zhong JY, Xu ZQ, Zhang Y, Ramirez Solano MA, Zhu W, Linton MF, Sheng Q, Kon V and Vickers KC: Dual inhibition of endothelial miR-92a-3p and miR-489-3p reduces renal injury-associated atherosclerosis. Atherosclerosis 282: 121-131, 2019.

26. Li Z, Shen J, Wu WK, Yu X, Liang J, Qiu G and Liu J: The role of leptin on the organization and expression of cytoskeleton elements in nucleus pulposus cells. J Orthop Res 31: 847-857, 2013.

27. Li Z, Liang J, Wu WK, Yu X, Yu J, Weng X and Shen J: Leptin activates RhoA/ROCK pathway to induce cytoskeleton remodeling in nucleus pulposus cells. Int J Mol Sci 15: 1176-1188, 2014

28. Ding F, Shao ZW and Xiong LM: Cell death in intervertebral disc degeneration. Apoptosis 18: 777-785, 2013.
29. Risbud MV and Shapiro IM: Role of cytokines in intervertebral disc degeneration: Pain and disc content. Nat Rev Rheumatol 10: 44-56, 2014.

30. Livak KJ and Schmittgen TD: Analysis of relative gene expression data using real-time quantitative PCR and the 2(-Delta Delta C(T)) method. Methods 25: 402-408, 2001.

31. Cildir G, Low KC and Tergaonkar V: Noncanonical NF- $\kappa \mathrm{B}$ signaling in health and disease. Trends Mol Med 22: 414-429, 2016.

32. Juniper M, Le TK and Mladsi D: The epidemiology, economic burden, and pharmacological treatment of chronic low back pain in France, Germany, Italy, Spain and the UK: A literature-based review. Expert Opin Pharmacother 10: 2581-2592, 2009.

33. Phillips C, Main C, Buck R, Aylward M, Wynne-Jones G and Farr A: Prioritising pain in policy making: The need for a whole systems perspective. Health Policy 88: 166-175, 2009.

34. Waddell G: Low back pain: A twentieth century health care enigma. Spine (Phila Pa 1976) 21: 2820, 1996.

35. Zhang YG, Sun Z, Zhang Z, Liu J and Guo X: Risk factors for lumbar intervertebral disc herniation in Chinese population: A case-control study. Spine (Phila Pa 1976) 34: 918-922, 2009.

36. Madera M, Brady J, Deily S, McGinty T, Moroz L, Singh D, Tipton $G$ and Truumees E; for the Seton Spine Rehabilitation Study Group: The role of physical therapy and rehabilitation after lumbar fusion surgery for degenerative disease: A systematic review. J Neurosurg Spine 26: 694-704, 2017.

37. Wang HQ, Yu XD, Liu ZH, Cheng X, Samartzis D, Jia LT, Wu SX, Huang J, Chen J and Luo ZJ: Deregulated mir-155 promotes Fas-mediated apoptosis in human intervertebral disc degeneration by targeting FAdd and caspase-3. J Pathol 225 : 232-242, 2011.

38. Ji ML, Lu J, Shi PL, Zhang XJ, Wang SZ, Chang Q, Chen H and Wang C: Dysregulated mir-98 contributes to extracellular matrix degradation by targeting IL-6/StAt3 signaling pathway in human intervertebral disc degeneration. J Bone Miner Res 31: 900-909, 2016.

39. Yu X, Li Z, Shen J, Wu WK, Liang J, Weng X and Qiu G: MicroRNA-10b promotes nucleus pulposus cell proliferation through RhoC-Akt pathway by targeting HOXD10 in intervetebral disc degeneration. PLoS One 8: e83080, 2013

40. Liu H, Huang X, Liu X, Xiao S, Zhang Y, Xiang T, Shen X, Wang $G$ and Sheng B: miR-21 promotes human nucleus pulposus cell proliferation through PTEN/AKT signaling. Int J Mol Sci 15: 4007-4018, 2014

41. Liu G, Cao P, Chen H, Yuan W, Wang J and Tang X: MiR-27a regulates apoptosis in nucleus pulposus cells by targeting PI3K. PLoS One 8: e75251, 2013.

42. Cheng X, Zhang L, Zhang K, Zhang G, Hu Y, Sun X, Zhao C, Li H, Li YM and Zhao J: Circular RNA VMA21 protects against intervertebral disc degeneration through targeting miR-200c and X linked inhibitor-of-apoptosis protein. Ann Rheum Dis 77: 770-779, 2018.

43. Zhang H, Li L, Yuan C, Wang C, Gao T and Zheng Z: MiR-489 inhibited the development of gastric cancer via regulating HDAC7 and PI3K/AKT pathway. World J Surg Oncol 18: 73, 2020.

44. Li F: Expression of miR-221 and miR-489 in breast cancer patients and their relationship with prognosis. Oncol Lett 19: 1523-1529, 2020.

45. Sun D, Yu M, Huang ZH, et al: Research progress in the action mechanism of miR-489 in tumors. Chem Life 37: 329-335, 2017.

46. Mohr AM and Mott JL: Overview of microRNA biology. Semin Liver Dis 35: 3-11, 2015

47. Yang YZ, Zhang YF, Yang L, Xu J, Mo XM and Peng W: MiR-760 mediates hypoxia-induced proliferation and apoptosis of human pulmonary artery smooth muscle cells via targeting TLR4. Int J Mol Med 42: 2437-2446, 2018.

48. Wang YC, Lin S and Yang QW: Toll-like receptors in cerebral ischemic inflammatory injury. J Neuroinflammation 8: 134, 2011.

49. Li WT and Zhang Q: MicroRNA-708-5p regulates mycobacterial vitality and the secretion of inflammatory factors in Mycobacterium tuberculosis-infected macrophages by targeting TLR4. Eur Rev Med Pharmacol Sci 23: 8028-8038, 2019.

50. Yang J, Chen Y, Jiang K, Yang Y, Zhao G, Guo S and Deng G: MicroRNA-106a provides negative feedback regulation in lipopolysaccharide-induced inflammation by targeting TLR4. Int J Biol Sci 15: 2308-2319, 2019.

51. Gong XY and Zhang Y: Protective effect of miR-20a against hypoxia/reoxygenation treatment on cardiomyocytes cell viability and cell apoptosis by targeting TLR4 and inhibiting p38 MAPK/JNK signaling. In Vitro Cell Dev Biol Anim 55: 793-800, 2019 
52. Wu D, Zheng C, Wu J, Huang R, Chen X, Zhang T and Zhang L: Molecular biological effects of weightlessness and hypergravity on intervertebral disc degeneration. Aerosp Med Hum Perform 88: 1123, 2017.

53. Wang J, Liew OJ, Richards AM and Chen YT: Overview of MicroRNAs in cardiac hypertrophy, fibrosis, and apoptosis. Int J Mol Sci 17: 749, 2016.

54. Cheng AM, Byrom MW, Shelton J and Ford LP: Antisense inhibition of human miRNAs and indications for an involvement of miRNA in cell growth and apoptosis. Nucleic Acids Res 33: 1290-1297, 2005.

55. Moro A, Driscoll TP, Boraas LC, Armero W, Kasper DM, Baeyens N, Jouy C, Mallikarjun V, Swift J, Ahn SJ, et al: MicroRNA-dependent regulation of biomechanical genes establishes tissue stiffness homeostasis. Nat Cell Biol 21: 348-358, 2019

56. Toyono T, Usui T, Villarreal G Jr, Kallay L, Matthaei M, Vianna LM, Zhu AY, Kuroda M, Amano S and Jun AS: MicroRNA-29b overexpression decreases extracellular matrix mRNA and protein production in human corneal endothelial cells. Cornea 35: 1466-1470, 2016.
57. Zhou J, Sun J, Markova DZ, Li S, Kepler CK, Hong J, Huang Y, Chen W, Xu K, Wei F and Ye W: MicroRNA-145 overexpression attenuates apoptosis and increases matrix synthesis in nucleus pulposus cells. Life Sci 221: 274-283, 2019.

58. Sun JC, Zheng B, Sun RX, Meng YK, Wang SM, Yang HS, Chen Y, Shi JG and Guo YF: MiR-499a-5p suppresses apoptosis of human nucleus pulposus cells and degradation of their extracellular matrix by targeting SOX4. Biomed Pharmacother 113: 108652, 2019.

(i) $(9)$ This work is licensed under a Creative Commons Attribution-NonCommercial-NoDerivatives 4.0 International (CC BY-NC-ND 4.0) License. 